\title{
Population trends of Mariana Crow Corvus kubaryi on Rota, Commonwealth of the Northern Mariana Islands
}

\author{
SHELDON PLENTOVICH, JOHN M. MORTON, JONATHAN BART, RICHARD \\ J. CAMP, MICHAEL LUSK, NATHAN JOHNSON and ERIC VANDERWERF
}

\section{Summary}

Endemic to the islands of Guam and Rota in the Mariana Islands, Mariana Crow Corvus kubaryi is the only corvid in Micronesia. Currently, it survives on Guam only because of translocation of individuals from Rota (1999-2003). Island-wide surveys in 1982 and 1995 on Rota yielded population estimates of 1,348 and 592 respectively, indicating a $56 \%$ decrease in only 13 years. A sharp decline in the only viable Mariana Crow population has serious implications for conservation efforts on Rota and for efforts to re-establish the Guam population. However, the validity of the apparent decline has been debated among scientists and government management agencies. We augmented the 1982 and 1995 island-wide VCP surveys with (I) an additional island-wide survey conducted in 1998, and (2) roadside surveys conducted during 1991-1993 and again during 1999-2002. We also outline historical changes in Rota's limestone forest based on aerial photographs and historical information. Data from all surveys indicate a significant decline in the Mariana Crow population. Declines occurred especially along the north-central coast and in the area east of the airport known as As Dudo in the 1990s, but the data indicate an island-wide decline over the entire span of the surveys. Introduced predators, human persecution, and habitat loss and degradation by anthropogenic and natural causes have all contributed to the decline. Long-term preservation of this species will require effective brown treesnake Boiga irregularis control, habitat protection, continued monitoring and research, and increased public education and awareness of Rota's rare and endangered species.

\section{Introduction}

Mariana crow Corvus kubaryi, known locally as Aga in Chamorro, is endemic to the islands of Guam and Rota in the Mariana archipelago. It is the only corvid in Micronesia (Jenkins 1983) and, barring the recovery and return of Hawaiian Crow Corvus hawaiiensis to the wild, the only corvid in all of the oceanic Pacific Islands. On Guam, crows were found historically in forested areas throughout the island and were considered common into the early 1960s (Seale 1901, Baker 1951, Jenkins 1983). However, in 1982 a U.S. Fish and Wildlife Service (USFWS) survey estimated only 357 crows on Guam, mostly in the northern cliff-line forests (Engbring and Ramsey 1984), and by 1985, Michael (1987) estimated there were only 100 on Guam. The most recent surveys, conducted in 2001 by the Guam Division of Aquatics and Wildlife (GDAWR), indicated a population of 16 crows (including 11 translocated from Rota), restricted to Andersen Air Force Base. Although predation by the introduced 
brown treesnake Boiga irregularis is now widely accepted as being responsible for this dramatic decline (Savidge 1987), other factors such as infertility, predation by rats Rattus spp. and monitor lizards Varanus indicus, mobbing by introduced drongos Dicrurus macrocercus, disruption by typhoons, and human disturbances (Morton 1996) have exacerbated population declines and may be preventing recovery. Disease (Savidge et al. 1992) and pesticides (Grue 1985) have been ruled out as contributing factors to both population declines and recovery efforts.

On Rota, in the Commonwealth of the Northern Mariana Islands (CNMI), Mariana Crows are widely distributed in both mature and secondary forests, but the population is apparently declining. Using the Variable Circular Plot (VCP) method, USFWS surveys suggested 1,348 crows on Rota in 1982 (Engbring et al. 1986), but only 592 crows in 1995, a 56\% decrease in only 13 years (Fancy et al. 1999). Fancy et al. (1999) believed that this decline was due to habitat loss, fragmentation and degradation, which they observed in the field and by comparison of aerial photographs of Rota taken in 1987 and 1994 .

A sharp decline in the only viable Mariana Crow population has serious implications for conservation efforts on Rota and for efforts to augment the Guam population by translocating birds from Rota. However, the validity of the apparent decline has been debated within the scientific community (see Duckworth et al. 1997, Morton et al. 1999, Mariana Crow Recovery Team 2001) and among various government management agencies. The results of surveys in 1982, 1995 and 1998 may not be directly comparable because the 1982 survey was conducted in April/May whereas the latter two surveys were conducted primarily in October (the October 1995 surveys were 23 October to Io November). The problem is compounded by changes in crow detectability before and after breeding and the potential inclusion of newly fledged young in the April/May surveys. Additionally, the validity of using the VCP method in this case has been questioned due to violations of model assumptions in the form of crow movement in response to observer presence (Mariana Crow Recovery Team 2001). Multiple detections from sequential stations may result from crows following the observers (Morton et al. 1999).

In this paper, we clarify the status and trend of the Mariana Crow population on Rota by compiling and evaluating all available survey data and other relevant information. We calculate population estimates from the 1998 VCP survey data, previously not analysed or published. Since the 1998 survey, the CNMI Division of Fish and Wildlife (DFW) also has conducted quarterly roadside point count surveys, herein termed "on-road surveys". We contrast them with more comprehensive VCP transects conducted in the forest (i.e. off-road). We also include data from other on-road surveys conducted quarterly from 1991 to 1993 (USFWS unpubl. data). Here, our goals were: (I) to attempt to provide a better understanding of historical changes in Rota's limestone forest by estimating forested habitat from aerial photographs taken in 1945 and making comparisons with more current data; (2) to examine on-road survey data collected quarterly from 1991 to 1993 (USFWS unpubl. data) and 1999 to 2002 (CNMI-DFW unpubl. data); (3) to re-analyse VCP data collected in April/May 1982 and October 1995 with improved distance sampling analyses methods, and analyse the October 1998 VCP survey data; and (4) to compare an estimate of the number of breeding pairs based on intensive field work from 1996 to 1999 (Morton et al. 1999) with the VCP estimates. 


\section{Methods}

Aerial photographs

Aerial photographs taken in 1945 were scanned and imported into ArcView (ESRI 1999). We outlined all forested areas on the image that were more than $50 \mathrm{~m}$ wide and then were able to calculate the percentage of Rota covered in forest. Because tree height was impossible to determine on the 1945 image, areas of short, scrubby secondary forests were included. These photographs were compared with vegetation surveys by Falanruw et al. (1989) which included 1976 aerial photographs and ground verification. All areas of limestone forest, atoll forest, and Casuarina forest (as determined by Falanruw et al. 1989) were compared with the forested areas outlined on the 1976 photo. We did not include introduced forest in our analysis because it is primarily composed of tangantangan Leucaena leucocephala, a reportedly allelopathic species that tends to grow in dense, homogeneous stands. There is no evidence from either Guam or Rota that crows nest in this forest type (C. Aguon and J. Morton pers. comm.). Tangantangan was initially used on Guam for hedges and later intentionally spread over much of the southern Marianas after World War (WW) II to prevent erosion (Perry and Morton 1999).

\section{On-road surveys}

Quarterly on-road surveys were conducted in two periods: (I) October 1991 to July 1993 and (2) August 1999 to June/July 2002 (Table 1). Counting points in 1991-1993 were separated by $0.40 \mathrm{~km}$, while points in 1999-2001 were separated by $0.80 \mathrm{~km}$. To make the data more directly comparable, points from both periods were plotted on a map and only data from points that were counted during both survey periods were used for analyses (Fig. $1, n=46$ points). Counts in 1991-1993 lasted 5 min whereas counts in 1999-2002 lasted $3 \mathrm{~min}$. We corrected for this difference by multiplying the earlier results by o.6. This method probably underestimates the numbers of crows recorded during the first 3 min of the 1991-1993 surveys, because the number of new birds recorded per minute probably decreases with time. In a study of Puerto Rican birds, where the numbers detected within $3 \mathrm{~min}$ and $5 \mathrm{~min}$ were recorded, the corresponding adjustment factor was 0.69 (J. Bart unpubl. data), which suggests that the error in using 0.60 was small. Moreover, because this method is conservative, it probably underestimates detections in earlier surveys (i.e. October 1991 to July 1993) and thus would not be responsible for any apparent declines.

We compared corrected crow numbers between the two periods by averaging data taken from like months within the same survey period (i.e. January 2000 was

Table 1. Timing of on-road Mariana Crow surveys conducted in 1991-1993 and 1999-2002 on the island of Rota, Commonwealth of the Northern Mariana Islands.

\begin{tabular}{llllll}
\hline Years & Aug & Oct & Jan & Apr & Jun/July \\
\hline 1991-1992 & & X & X & X & X \\
$1992-1993$ & & $X$ & $X$ & $X$ & $X$ \\
$1999-2000$ & $X$ & $X$ & $X$ & $X$ \\
$2000-2001$ & & $X$ & $X$ & $X$ \\
$2001-2002$ & & $X$ & $X$ & $X$ & $X$ \\
\hline
\end{tabular}




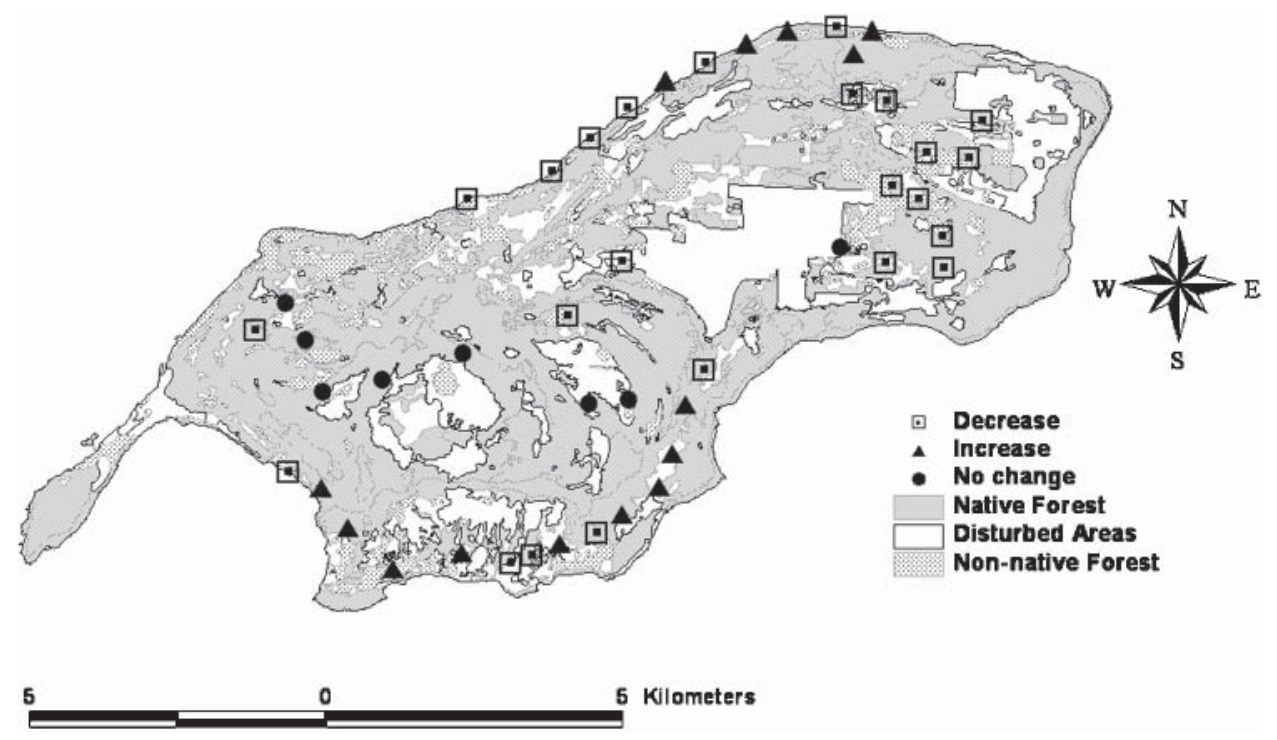

Fig. 1. Location of on-road survey points where Mariana Crow detections decreased, increased or remained stable during surveys conducted in 1991-1993 and again in 1999-2002 in relation to disturbed and undisturbed land on the island of Rota, Commonwealth of the Northern Mariana Islands.

averaged with January 2001, etc.) and then calculating a simple mean of all months. Data collected in August 1999 was omitted because no other August surveys were conducted in either period (Table 1 ).

\section{Off-road surveys}

Off-road surveys were conducted in April/May 1982, October/November 1995 and October 1998. Trained observers conducted $8 \mathrm{~min}$ VCP counts at stations located approximately every $150 \mathrm{~m}$ on 13 transects in 1982 (211 stations), and 17 transects in 1995 and 1998 (311 and 314 stations respectively; Fig. 2) and recorded the distance to each crow detected, either audibly or visually. Surveys were conducted during a $4 \mathrm{~h}$ period following sunrise on days when weather conditions did not interfere with detecting birds (see Scott et al. 1986). Observers practised estimating distances for 3 days prior to the survey to reduce errors in distance estimation associated with observer variability. A Global Positioning System was used to record longitude and latitude to facilitate future station location.

\section{Estimate of breeding pairs}

The estimate of breeding pairs was based on three sources: (I) mapping of all breeding pairs on six study plots during an intensive investigation of crow demographics from October 1996 to October 1999 (Morton et al. 1999); (2) mapping of breeding pairs elsewhere on the island that were observed from 1990 to 1999 with corroboration by CNMI-DFW biologists (M. Lusk, S. Taisacan, D. Worthington); and (3) extrapolating 


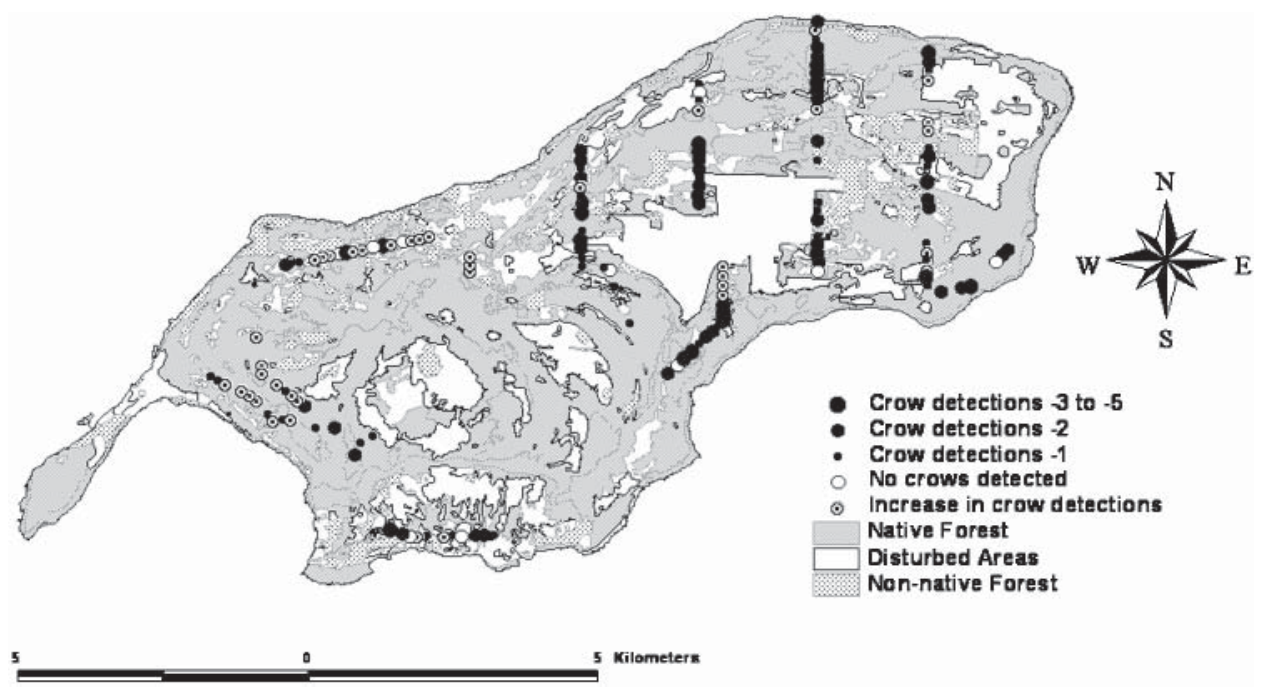

Fig. 2. Trends in Mariana Crow detections between off-road surveys conducted in 1982 and 1995 on the island of Rota, Commonwealth of the Northern Mariana Islands.

the pair density estimate from the six study plots to forested areas that were not visited regularly enough to determine the breeding status or numbers of crows.

Breeding by Mariana Crow was investigated on six plots of approximately $\mathrm{I} \mathrm{km}^{2}$ each, encompassing 580 ha and approximately $10 \%$ of the native forest on Rota (Fig. 3). The six study plots were selected because they formed some of the largest patches of contiguous native forest on Rota (Morton et al. 1999). These plots were

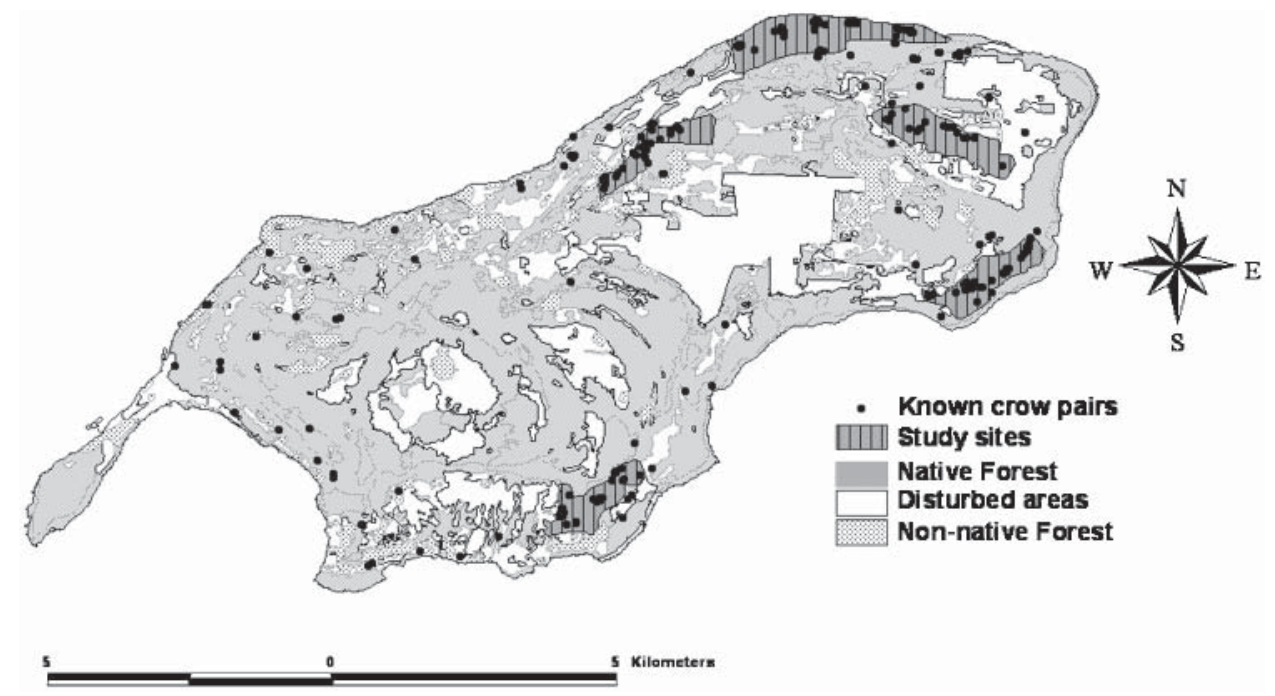

Fig. 3. Location of known Mariana Crow pairs in relation to native forest and study sites on the island of Rota, Commonwealth of the Northern Mariana Islands. 
searched at least once a week (usually two or three times) by a team of one to six biologists. Searches were conducted in the morning (o6hoo-11hoo) and late afternoon (I5hoo-18hoo). All crow observations were recorded, with special attention given to simultaneous pair observations, nesting activity, family groups, and observations of banded individuals.

In addition to these six study plots, Service and CNMI-DFW biologists searched for crow nests in many areas of Rota in the past decade. Since 1990, 71 crows have been banded on Rota: five as adults, two of unknown age, 19 as juveniles prior to October 1996, and 45 as juveniles during the 3 years of the Morton et al. (1999) study. Observations of banded birds, repeated sightings of family groups in the same general location over several years, and finding and monitoring active nest-sites constituted the basis for the identification of locations of breeding pairs.

Lastly, the pair density estimate from the six study plots was extrapolated to several areas that were roadless, had good limestone forest, and were known to contain crows but were not visited regularly enough to determine numbers. These areas were widely spread over Rota and include As Funta, Gampapa, As Dudo, below Finata, north of the airport, and above and south-east of Gauyaugan.

\section{Data analysis}

Change in population size was calculated by comparing the mean number of crows recorded per station each year (on-road and off-road surveys) and by using distance methods (off-road surveys only). Means per station were calculated using only stations surveyed during every survey and acknowledging the two-stage sampling design. For the off-road surveys, the mean for a given year (1982, 1995 or 1998) was $\frac{1}{n} \sum_{i}^{n} x_{i j}$ where $x_{i j}$ is the number of crows recorded at station $j$ on transect $i$ and $n$ is the number of transects surveyed during each year (II). For the on-road surveys, the mean per station within a period (1990-1993 or 1999-2001) was $\frac{1}{n} \sum_{i}^{n} \bar{x}_{i j}$ where $\bar{x}_{i j}$ is the mean number of crows recorded during month $j$ at station $i$ (e.g. the mean of the numbers recorded in October 1990 and October 1992) and $n$ is the number of stations surveyed on every occasion (46).

Change was defined as the ratio, $\overline{\boldsymbol{x}}_{2} / \overline{\boldsymbol{x}}_{1}$, where $\overline{\boldsymbol{x}}_{1}$ and $\overline{\boldsymbol{x}}_{2}$ are the means from 2 years (off-road surveys) or periods (on-road surveys). The standard error of $\overline{\boldsymbol{x}}_{2} / \overline{\boldsymbol{x}}_{1}$ was estimated as $\left.\operatorname{se}\left(\bar{x}_{2} / \bar{x}_{1}\right)=\left(\bar{x}_{2} / \bar{x}_{1}\right)\left(c v\left(\bar{x}_{2}\right)^{2}+c v\left(\bar{x}_{1}\right)^{2}\right)\right)^{0.5}$, a standard formula for the ratio of independent random variables. The statistical significance of changes was estimated using $t$-tests with standard error calculated with the degrees of freedom equal to the number of transects (II) for the off-road surveys and the number of stations (46) for the on-road surveys ("ratio of means" approach; Cochran 1977). This approach assumes that transects and stations are random samples from Rota or from crow habitat on Rota.

Distance data were analysed using program DISTANCE and VCPDATA (Scott et al. 1986, Fancy 1997, Thomas et al. 2001). Covariables were tested for differences under actual conditions (observer, time and weather variables) to the reference conditions (multiple regression analysis with a reference observer, time sampled at oghoo, and no cloud cover, rain or wind) to account for sampling variance. No differences were found between reference conditions and actual conditions. Model selection was 
a priori restricted to half-normal with a hermite polynomial adjuster, hazard-rate with a simple polynomial adjuster, and uniform with cosine adjuster. Effective detection radius (EDR) and per cent coefficient of variation $(\% \mathrm{CV})$ values for the 1982 survey followed Fancy et al. (1999) ( $E D R=128.880 \mathrm{~m}, \% \mathrm{CV}=7.8 \mathrm{I})$. EDR and \%CV values were calculated for pooled 1995 and 1998 surveys. Population estimates were calculated by multiplying density by survey area (6,057 ha for All Habitats and 2,826 ha for Breeding and Foraging Habitat). Information on breeding and foraging habitat was included as it probably provides the most accurate population estimates.

Model selection for both 1995 and 1998 data, pooled, was achieved with a truncation of $158.0 \mathrm{~m}$ and 157 observations. The best-fit model was a uniform function with cosine series expansion of order one. No evidence to reject the model was found with chi-square goodness-of-fit analysis $\left(\chi^{2}=26.037, \mathrm{df}=16, P=0.054\right)$. Annual density estimates were calculated using the pooled EDR and \%CV values and data pertaining from independent census efforts only (1998 and 1995 data not pooled).

To better understand potential biases present in comparing off-road survey data collected in April/May versus October, we used the year-round on-road survey data to evaluate crow detectability in January, April, June/July and October. Survey results collected in 1991-1992, 1992-1993, 1999-2000 and 2000-2002 were compared.

\section{Results}

\section{Aerial photographs}

In 1945, an estimated $50.5 \%(4,276.9$ of $8,466.5$ ha) of Rota was covered in native forest. In 1976 an estimated $60.4 \%(5,151.6$ of 8,522.6 ha) was covered in native forest. The small discrepancy in total area covered in 1945 versus $1976(8,466.5$ and $8,522.6$, respectively) is due to the distortion present when the 1945 maps were scanned and we believe it to be insignificant for the identification of large-scale changes in forest cover we present.

\section{Population trends}

The numbers of crows recorded per station declined substantially in both surveys (Table 2). In the off-road survey, the mean per station declined by $54 \%$ between 1982

Table 2. Mean number of Mariana Crow recorded per station during off-road surveys throughout Rota in April/May 1982, October 1995 and October 1998.

\begin{tabular}{|c|c|c|c|c|c|}
\hline \multirow[b]{2}{*}{ Variable } & \multicolumn{3}{|c|}{ Means/station } & \multicolumn{2}{|l|}{ Declines } \\
\hline & 1982 & 1995 & 1998 & 1982 to 1995 & 1982 to 1998 \\
\hline Crows/station & 1.12 & 0.52 & 0.19 & $54 \% * * *$ & $83 \% * * *$ \\
\hline Standard error & 0.16 & 0.13 & 0.07 & $13 \%$ & $7 \%$ \\
\hline Distance estimate ${ }^{\mathrm{a}}$ & 1098 & 680 & 356 & $38 \% * * *$ & $67 \% * * *$ \\
\hline Standard error & 114 & 92 & 61 & $6 \%$ & $6 \%$ \\
\hline
\end{tabular}

$* * * P<0.001$.

${ }^{a}$ For all habitats. Estimates for breeding and foraging habitats (and SEs) during 1982, 1995 and 1998 were 780 (81), 483 (65) and 253 (43), respectively. The declines and their SEs, calculated from these estimates, were identical to the declines calculated from the All Habitats analysis. 
and 1995 and by $83 \%$ between 1982 and 1998. Both changes were significant $(P<0.001)$. The VCP estimate declined by $38 \%$ between 1982 and 1995 and by $67 \%$ between 1982 and 1998. Both of these changes were also significant. We repeated the mean/station analysis of the off-road data using all stations surveyed in each year, and results were similar. The decrease between 1982 and 1995 was 51\%, and the decrease between 1982 and 1998 was $76 \%$. The proportion of stations with at least one crow detected (using all stations surveyed in each year) was $52 \%$ in $1982,28 \%$ in 1995 and $18 \%$ in 1998 . Between 1982 and 1998, crow detections declined at 99 stations and increased at only 19 stations.

In the on-road survey, the mean number of birds recorded per station point declined by $45 \%$ from 0.22 in 1991-1993 to 0.12 during 1999-2002 (paired $t$-test: $t=2.46 ; \mathrm{df}=45 ; P=0.017$ ). The numbers of crows recorded per station decreased over this period at 26 points, increased at 12 points, and no crows were detected at eight points (Fig. I). Declines were most evident in the north-central coast and east of the airport in the area known as As Dudo. Since off-road surveys were conducted in April and October, we closely examined on-road survey data from those months and found that the same number or fewer crows were detected in April versus October in all four survey periods. In fact, according to our on-road survey data crows were more detectable in October than in January, April or June/July ( $t=2.63, \mathrm{df}=7, P=0.03$; Fig. 4).

\section{Population size}

A total of 85 known Mariana Crow pairs were identified island-wide (Fig. 3), most of which have known nest-sites or have been observed repeatedly over 5 years with associated family groups. Of these pairs, 31 were identified on the six study plots used by Morton et al. (1999). Mean pair density from these six study plots was I pair per 22.0 \pm 3.5 ha of forested habitat (Morton et al. 1999).

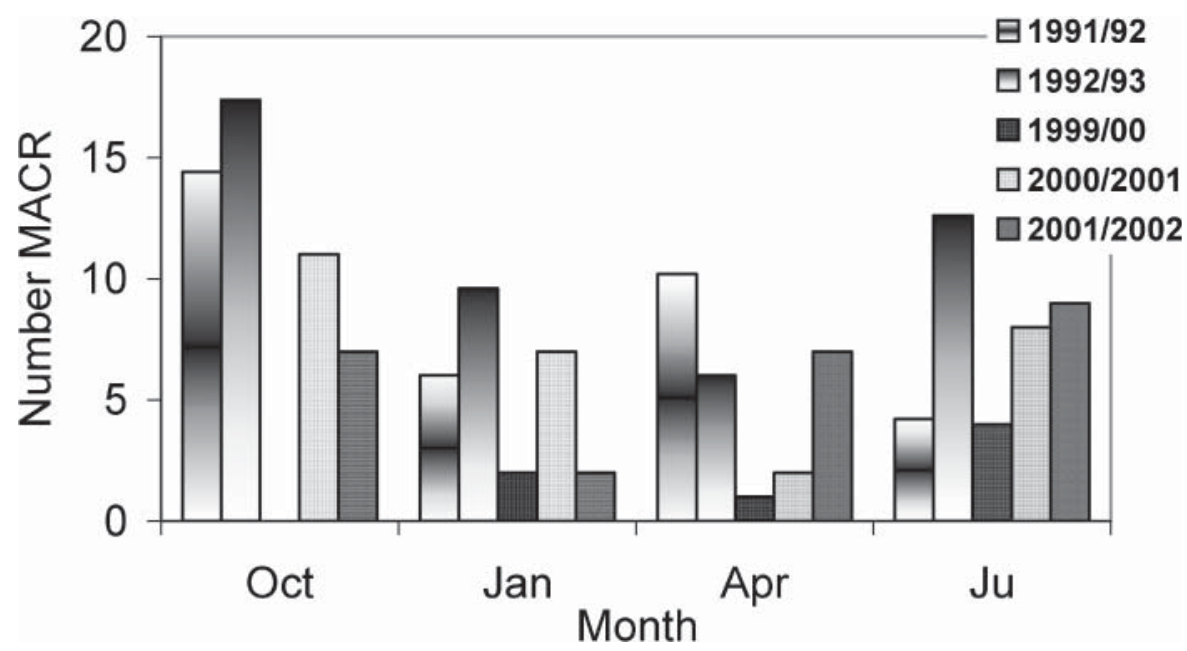

Fig. 4. Number of Mariana Crows detected by month in 1991-1993 and 1999-2002 surveys on the island of Rota, Commonwealth of the Northern Mariana Islands. October 1999/oo not surveyed. 
Table 3. Forested habitat outside Mariana Crow study sites on Rota, Commonwealth of the Northern Mariana Islands.

\begin{tabular}{llll}
\hline Area name & Location & Area (ha) & Known pairs \\
\hline As Funta & North-central region & 175 & 1 \\
Gampapa & Inland, eastern region & 115 & 0 \\
As Dudo & Coast, eastern region & 85 & 0 \\
Finata & South-central region & 55 & 0 \\
Gauyaugan & Southwest region & 85 & 0 \\
North of Airport & Eastern, central region & 240 & 1 \\
\hline Total & & 755 & 2 \\
\hline
\end{tabular}

There are approximately 755 ha of forested habitat within the areas known as As Funta, Gampapa, As Dudo, Finata, north of the airport, and Gauyaugan (Table 3). Extrapolating the above density estimate to these poorly surveyed areas suggests that 34 pairs $(95 \% \mathrm{CI}=26-50)$ may be breeding there. Two of these pairs are well documented and have been previously mapped (Fig. 3). Consequently, 32 additional pairs are estimated to occur in these areas, suggesting an island-wide estimate of 117 Mariana Crow pairs.

The number of pairs on the six study plots was relatively constant during the 4 years of intensive monitoring. The extent of individual turnover is unknown because such a small proportion of the breeding adults on the study sites were banded. Two instances of turnover were verified in rare cases where breeding adults were banded. In both cases, adults were quickly replaced.

\section{Discussion}

Has the Mariana Crow population declined?

Rota's crow population declined substantially between April 1982 and October 1998. Off-road surveys indicated a $73 \%$ decrease in mean detections per station during this 17-year period (Table 2). On-road surveys similarly indicated a $45 \%$ decrease in mean detections per station between 1991-1993 and 1999-2002. Despite any intrinsic biases that either survey method may have had, both showed an apparent and substantial decline in the Mariana Crow population on Rota.

We believe the VCP method is a reasonable population estimation technique for Mariana Crow. We attempted to address possible violations of distance sampling assumptions (Buckland et al. 2001) by having all observers complete calibration exercises in the field before sampling, to increase the accuracy of their distance estimates. We also visually inspected frequency histograms and found no evidence of assumption violations.

We questioned the effects of seasonality on crow detection rates. Since the 1982 surveys were conducted in April/May and the 1995 and 1998 surveys were conducted primarily in October, we were concerned that the high number of recently fledged young in April and May could increase crow detections. Our on-road survey data revealed that crows were more detectable in October than in January, April, or June/ July (Fig. 4). Thus, any declines between the April/May 1982 off-road survey and the October 1995 and 1998 off-road surveys would be despite seasonal differences in 
detectability not because of it. On-road survey data suggested that the estimate of birds per station (1.06) in the April/May 1982 off-road survey probably underestimated the population because crows were less detectable at that time. Based on 4 years' data (surveys were not conducted in October 1999), the number of crows detected in October was 1.9 times higher than in April. Applying this ratio to the point count data collected in April/May 1982, we would expect an October survey of the same population to result in 2.0 birds per station. In 1995, our calculation of birds per station was 0.43 , indicating a substantial decline.

Interpretation of off-road survey data was further complicated by the occurrence of two super-typhoons in November and December 1997. Super-typhoons Keith and Paka essentially truncated the breeding effort during the 1997-1998 season; only 14\% of known pairs successfully fledged young that season (Morton et al. 1999). Consequently, towards the end of the wet season (August) in 1998, virtually the entire crow population was both synchronized and available for breeding. The third off-road survey was conducted during October 1998, when many of the monitored crow pairs were building nests or incubating clutches. Mean detections per station in October/ November 1995 and October 1998 declined significantly. In contrast, from October 1996 to October 1999, the number of Mariana Crow pairs that used six study plots was essentially constant, varying from 28 to 30 (Morton et al. 1999).

We suggest three possible factors that could create a situation in which the number of crows detected in October 1998 was significantly less than in October 1995, despite no apparent change in the number of breeding pairs being studied on six study plots during the same interval. First, eight of the off-road transects passed through parts of the six study plots where all breeding pairs were monitored between 1996 and 1999 . At least 23 pairs (46 individuals) were known to use forest within $150 \mathrm{~m}$ of VCP stations, but only 37 crows (80\% of known adults) were detected during the 1998 survey. We attribute the reduced detections to the fact that most pairs on the study blocks were synchronized and in the early stages of nesting after the typhoon and consequently more secretive compared with those surveyed in October 1995. However, unbiased estimates can be produced when up to $60-80 \%$ of the target objects are missed (Buckland et al. 2001). Second, the population in October 1998 had a significantly smaller juvenile cohort because the number of pairs that fledged young was $22-26 \%$ of the rates the season before and after 1997-1998. Third, it is possible that the demographics on the six study plots were different than elsewhere on the island during this interval, but we believe this is unlikely as limestone forest on these study plots and elsewhere on Rota was similar in species and structural composition.

\section{What is the current population of Mariana Crow?}

Despite these concerns about seasonality and VCP methodology, we believe that the most recent VCP estimates approximate the current population as determined from actual pair identification. Our best population estimate is that Rota has 117 breeding pairs or 234 adults. This estimate is similar to our pooled estimate from the 1995 and 1998 data and well within the $95 \%$ confidence intervals. All evidence from Rota and Guam suggests that survivorship in the adult cohort is high. Much of the annual variation in the population probably results from catastrophic changes in reproductive output as a result of typhoons and the unknown status of the subadult population (i.e. "floaters"). Morton et al. (1999) determined that Mariana Crows may enter the 
subadult cohort as early as 3 months after fledging and typically enter the adult cohort at 3.5 years (although the latter was based on a small sample size). Survivorship of this cohort may have changed in the past two decades for unknown reasons. This may explain why flocks of Mariana Crow, common in the 1970s and early 1980s, have been rarely observed recently (Wiles 1998).

\section{Why has the Mariana Crow population declined?}

Several factors may have contributed to the population decline, including introduced predators, human persecution, and habitat loss and degradation from both anthropogenic and natural causes. The importance of these factors probably varied during the past century. The Japanese occupied the CNMI in 1914 during WWI and rapidly developed industries immediately prior to WWII. There were only 500 Chamorros and a few Carolinians on Rota in early 1930. However, sugarcane farming and phosphate mining, begun in 1930 resulted in an increase in population and modernization. By 1935, there were almost 6,000 residents on Rota. During WWII, Rota escaped invasion but was incidentally bombed by U.S. aircraft returning to Guam (Farrell 1991). By the end of WWII, the forest on Rota may have been in its most degraded state during the twentieth century; aerial photography confirms that $50 \%$ of Rota was cleared by 1945 .

By 1976, 60\% of Rota was covered in forest. Although these data indicate only a 10\% increase in forest coverage over three decades, this is somewhat misleading. The forest matured over this period and was 30-40 years old when the first VCP survey was conducted. Much of the secondary limestone and strand forest that regenerated was found to have relatively high crow productivity in the late 1990s (Morton et al. 1999). Primary limestone forest, as designated by Falanruw et al. (1989), existed on areas that were not logged by the Japanese (generally due to excessively steep terrain) during the 1930s. By April 1982, when the crow population was estimated to be $>1,300$, total forest coverage and maturity may have been the greatest since the Japanese first arrived on Rota.

In January 1988, however, super-typhoon Roy struck Rota with winds exceeding $240 \mathrm{~km} / \mathrm{h}$ (130 kts). Virtually the entire forest on Rota was defoliated, and in some areas $50 \%$ of large trees were downed and 100\% suffered major limb damage. Anecdotal observations by several local biologists indicate a forest with a previously closed canopy that was severely damaged (Fancy and Snetsinger 1996). The forest had not recovered 7 years later when the October/November 1995 surveys were conducted. The low population estimate at that time (fewer than 600 Mariana Crow) was probably due to habitat degradation.

In December 1997, super-typhoon Paka truncated the nesting activity of crows that were being studied and synchronized the breeding activity the following year (Morton et al. 1999). The October 1998 off-road surveys estimated a population of only 356 Mariana Crow. Potential reasons for this especially low estimate were discussed above.

The patterns we observed in our off-road surveys suggest that the number of crow detections decreased island-wide between 1982 and 1998 (Fig. 2). However, the onroad surveys suggest that the population decline since 1991 was near the Rota Resort, which was built in 1992 (Worthington 1998), and agricultural lands east of the airport (Fig. 2). This pattern may be coincidental, but we believe that land development and possibly human persecution caused the population decline in recent years. Persecution 
of adult crows was verified during the construction of the Rota Resort when two adults were shot (M. Lusk pers. comm.). The deliberate killing of adults is alarming because Population Viability Analysis models suggest that adult survivorship is the most important demographic parameter in maintaining the Mariana Crow population (USFWS 2003).

In summary, Rota's Mariana Crow population has declined substantially in the last two decades. Persecution of adult crows by people with the perception that the crow is impeding their access to homestead lands is the newest and most immediate threat to the population. Continuing public education encouraging local pride in Rota's unique ecosystem is critical to the survival of the crow. In addition, long-term protection of the Mariana Crow will require continued monitoring, additional research into the more subtle threats that may be causing the population to decline, continued brown treesnake control, habitat protection, and the restoration of a healthy Mariana Crow population on Guam.

\section{Acknowledgements}

This synthesis was only possible due to information and feedback from numerous people. Dr Seb Buckton, Dr Douglas Pratt and members of the Mariana Crow Recovery Team provided comments on all or portions of this manuscript. Funding for offroad surveys was provided by USFWS. Surveys were conducted collaboratively with personnel from USFWS, CNMI-DFW and GDAWR. On-road surveys were funded and conducted by CNMI-DFW personnel. John Engbring helped to clarify data he collected in 1982 and during the roadside surveys in the early 1990s. Stan Taisacan helped to identify and verify Mariana Crow pairs located outside the study blocks throughout our time on Rota. Annie Marshall, Fred Amidon, Tino Aguon, Glenn Desy, Becca Dymzarov Jim Herriges, Shanie Holman, Jane Jackson, Shona Lawson, Tina Lee, Kim Livengood, Brigid O’Neil, Meaghan Parker, Mark Philippart, Shane Pruett, Robert Reed, Tom Reid, Michelle Rogne, Joey Shousky, Nicole Shutt, Lance Tanino, Mike Vamstad, Elaine Wells, Chris Willet and Sarah Wyshynski provided crucial help in the field conducting surveys and/or locating breeding pairs.

\section{References}

Aguon, C. G. (1990) The current distribution and abundance of the Mariana crow, Corvus kubaryi, on Guam. Unpublished report. Agana, Guam: Division of Aquatic and Wildlife Resources, Guam Department of Agriculture.

Baker, R. H. (1951) The avifauna of Micronesia, its origin, evolution, and distribution. University of Kansas Publ. Museum of Natural History 3: 1-359.

Buckland, S. T., Anderson, D. R., Burnham, K. P., Laake, J. L., Brochers, D. L. and Thomas, L. (2001) Introduction to distance sampling: estimating abundance of biological populations. Oxford: Oxford University Press.

Cochran, W. G. (1977) Sampling techniques. New York: Wiley.

Conry, P. J. (1988) High nest predation by brown tree snakes on Guam. Condor 90: 478-482.

Duckworth, W. D., Beissinger, S. R., Derrickson, S. R., Fritts, T. H., Haig, S. M., James, F. C., Marzluff, J. M. and Rideout, B. A. (1997) The scientific bases for preservation of the Mariana crow. Committee on the Scientific Bases for the Preservation of the Mariana Crow, National Research Council. Washington, D.C.: National Academy Press. 
Engbring, J. and Ramsey, F. L. (1984) Distribution and abundance of the native forest birds of Guam. Results of a 1981 survey. Washington, D.C.: U.S. Fish and Wildlife Service (FWS/OBS-84/20).

Engbring, J., Ramsey, F. L. and Wildman, V. J. (1986) Micronesian forest bird survey, 1982: Saipan, Tinian, Aguijan, and Rota. U.S. Fish and Wildlife Report. Honolulu, HI: U.S. Fish and Wildlife Service.

Falanruw, M. C., Cole, T. G. and Ambacher, A. H. (1989) Vegetation survey of Rota, Tinian, Saipan, Commonwealth of the Northern Marianas. Berkeley, CA: USDA, U.S. Forest Service, Pacific Southwest Forest and Range Experiment Station (Resour. Bull. PSW-27).

Fancy, S. G. (1997) A new approach for zing bird densities from variable circular-plot counts. Pacific Sci. 51: 107-114.

Fancy, S. G. and Snetsinger, T. J. (1996) Potential reasons for the decline of the bridled whiteeye population on Rota, Mariana Islands. USGS, BRD, Pacific Island Ecosystems Research Center, Hawaii.

Fancy, S. G., Lusk, M. R. and Grout, D. (1999) Status of the Mariana crow population on Rota, Mariana Islands. Micronesica 32: 3-10.

Farrell, D. A. (1991) History of the Northern Mariana Islands. Saipan, Commonwealth of the Northern Mariana Islands: Public School System.

Grue, C. E. (1985) Pesticides and the decline of Guam's native birds. Nature (Scientific Correspondence) 316: 301 .

Jenkins, J. M. (1983) The native forest birds of Guam. Washington, D.C.: American Ornithologists' Union (Ornithol. Monogr. No. 31).

Mariana Crow Recovery Team (2001) Meeting minutes, June 2001.

Michael, G. A. (1987) Notes on the breeding biology and ecology of the Mariana or Guam Crow. Avicult. Mag. 93:73-82.

Morton, J. M. (1996) The effects of aircraft overflights on endangered Mariana crows and Mariana fruit bats at Andersen Air Force Base, Guam. Prepared for U.S. Navy, PACNAVFACENGCOM, Pearl Harbor. Honolulu, HI: U.S. Fish and Wildlife Service, Pacific Islands EcoRegion.

Morton, J. M., Plentovich, S. and Sharp, T. (1999) Reproduction and juvenile dispersal of Mariana crows (Corvus kubaryi) on Rota, 1996-1999. Honolulu, HI: U.S. Fish and Wildlife Service, Pacific Islands EcoRegion.

Perry, G. and Morton, J. M. (1999) Regeneration rates of the woody vegetation of Guam's Northwest Field following major disturbance: land use patterns, feral ungulates, and cascading effects of the brown treesnake. Micronesica 32: 125-142.

Savidge, J. A. (1987) Extinction of an island forest avifauna by an introduced snake. Ecology 68: 66o-668.

Savidge, J. A., Sileo, L. and Siegfried, L. M. (1992) Was disease involved in the decimation of Guam's avifauna? J. Wildl. Dis. 28: 206-214.

Seale, A. (1901) Report of a Mission to Guam. Occ. Papers Bernice P. Bishop Museum. 1: 17128.

Scott, J. M., Mountianspring, S., Ramsey, F. L. and Kepler, C. B. (1986) Forest bird communities of the Hawaiian Islands: their dynamics, ecology, and conservation. Studies in Avian Biology 9. Lawrence, Kamsas: Allens Press Inc.

Thomas, L., Laake, J. L., Strindberg, S., Marques, F., Borchers, D. L., Buckland, S. T., Anderson, D. R., Burnham, K. P., Hedley, S. L. and Pollard, J. H. (2001) Distance 4.o. Beta 2. University of St Andrews, U.K.: Research Unit for Wildlife Population Assessment.

USFWS, U.S. Fish and Wildlife Service (1990) Native forest birds of Guam and Rota of the Commonwealth of the Northern Mariana Islands recovery plan. Portland, OR: U.S. Fish and Wildlife Service.

USFWS, U.S. Fish and Wildlife Service (2003) Mariana Crow (Corvus kubaryi) Draft Recovery Plan. Portland OR: U.S. Fish and Wildlife Service. 
Wiles, G. J. (1998) Records of communal roosting in Mariana crows. Wilson Bull. 110: 126-128. Worthington, D. (1998) Inter-island dispersal of the Mariana Common Moorhen: a recolonization of an endangered species. Wilson Bull. 110: 414-441.

SHELDON PLENTOVICH* ${ }^{*}$ and ERIC VANDERWERF

Department of Zoology, Edmondson Hall 152, 2538 McCarthy Mall, University of Hawaii, Honolulu, HI 96822-2279, U.S.A.

\section{JOHN M. MORTON}

U.S. Fish and Wildife Service, Kenai National Wildlife Refuge, P.O. Box 2139, Soldotna, AK 99669, U.S.A.

\section{JON BART}

Snake River Field Station, 970 Lusk Street, Boise, ID 83706, U.S.A.

\section{RICHARD J. CAMP}

Pacific Cooperative Studies Unit (University of Hawaii), U.S. Geological Survey, Pacific Island Ecosystems Research Center, PO Box 44, Hawaii National Park, HI 96718, U.S.A.

\section{MICHAEL LUSK}

U.S. Fish and Wildlife Service, Cabeza Prieta National Wildlife Refuge, 1611 North Second Avenue, Ajo, AZ 85321, U.S.A.

\section{NATHAN JOHNSON}

CNMI-Division of Fish and Wildlife, P.O. Box 1397, Rota, MP 96951

Current address: USGS Forest and Rangeland Ecosystem Science Center, 3200 SW Jefferson Way, Corvallis, OR 97331, U.S.A.

*Author for correspondence; E-mail: plentovi@hawaii.edu

Submittted 3 October 2003; revision accepted 3 November 2004 